\title{
Two-year general and neurodevelopmental outcome after neonatal complex cardiac surgery in patients with deletion 22q11.2: A comparative study
}

Joseph Atallah, MD, ${ }^{a}$ Ari R. Joffe, MD, ${ }^{a}$ Charlene M. T. Robertson, MD, ${ }^{a, c}$ Norma Leonard, MD, ${ }^{b}$ Patricia M. Blakley, MD, PhD, ${ }^{d}$ Alberto Nettel-Aguirre, PhD, ${ }^{\text {e,f }}$ Reg S. Sauve, MD, ${ }^{e}$ David B. Ross, MD, ${ }^{g}$ Ivan M. Rebeyka, MD, ${ }^{9}$ and the Western Canadian Complex Pediatric Therapies Project Follow-up Group ${ }^{h}$

From the Departments of Pediatrics, ${ }^{\text {a }}$ Medical Genetics, ${ }^{\mathrm{b}}$ and Surgery, ${ }^{\mathrm{g}}$ University of Alberta, Edmonton, Alberta, Canada; Neonatal and Infant Follow-up Clinic, ${ }^{\mathrm{c}}$ Glenrose Rehabilitation Hospital, Edmonton, Alberta, Canada; Department of Pediatrics, ${ }^{\mathrm{d}}$ University of Saskatchewan, Saskatoon, Saskatchewan, Canada; Department of Pediatrics, ${ }^{\text {e }}$ University of Calgary, Calgary, Alberta, Canada; Biostatistician, ${ }^{\mathrm{f}} \mathrm{Re}-$ search Methods Team, Faculty of Medicine, University of Calgary, Calgary, Alberta, Canada; D. Moddemann, Winnipeg, Manitoba, Canada; A. Ninan, Regina, Saskatchewan, Canada. ${ }^{\text {h }}$

Financial support was initially provided by the Glenrose Rehabilitation Hospital research trust fund, with ongoing funding from the Registry and Follow-up of Complex Pediatric Therapies Project, Alberta Health and Wellness.

Received for publication Dec 19, 2006; revisions received Feb 2, 2007; accepted for publication March 14, 2007.

Address for reprints: Ari R. Joffe, MD, FRCP(C), Department of Pediatrics, 3A3.07 Walter C Mackenzie Center, 8440- 112 St, Edmonton, Alberta, Canada T6G 2B7 (E-mail: ajoffe@cha.ab.ca).

J Thorac Cardiovasc Surg 2007;134:772-9

$0022-5223 / \$ 32.00$

Copyright (๑) 2007 by The American Association for Thoracic Surgery

doi:10.1016/j.jtcvs.2007.03.007
Objective: Neonatal complex cardiac surgery carries a significant risk for adverse neurodevelopmental outcome. We hypothesized this risk to be higher in patients with deletion 22q11.2.

Methods: From 1996 to 2004, neonates who had complex cardiac surgery at age 6 weeks or less had multisite, multidisciplinary health and neurodevelopmental outcomes (Bayley Scales of Infant Development II; mental and psychomotor developmental indices [MDI, PDI] as mean [SD] and delay [ $<70]$ ) assessed at 18 to 24 months of age. All 16 patients with deletion 22q11.2 (group 1) were compared with 16 patients without deletion 22q11.2 (group 2) having undergone neonatal complex cardiac surgery at the same center and matched for cardiac lesion, socioeconomic status, and year of operation. Outcomes were compared by univariate and multivariate analyses.

Results: Heart lesions in each group consisted of 6 (37.5\%) cases of interrupted aortic arch, $6(37.5 \%)$ cases of truncus arteriosus, and $4(25 \%)$ cases of tetralogy of Fallot. Outcomes were available for all survivors. Mortality was $3(19 \%)$ and $1(6 \%)$ in groups 1 and 2 , respectively $(P=.6)$. MDI and PDI scores were $66.1(10.6)$ and 55.0 (9.4) for group 1 and 86.3 (14.6) and 82.3 (14.3) for group $2(P<.001)$. Only deletion 22q11.2 was significant in stepwise multiple regression to predict MDI and PDI scores. Mental delay occurred in $8(61.5 \%)$ of 13 in group 1 and $2(13.8 \%)$ of 15 in group $2(P=.016)$. Psychomotor delay occurred in $11(84.6 \%)$ of 13 in group 1 and $1(6.7 \%)$ of 15 in group $2(P<.001)$.

Conclusion: Neonates affected by deletion 22q11.2 and having neonatal complex cardiac surgery have significantly worse neurodevelopmental outcome than do those without deletion 22q11.2.

$\mathrm{S}$ everal studies have demonstrated that some neonates and infants undergoing complex cardiac surgery (CCS) for congenital heart disease (CHD) have an abnormal neurodevelopmental outcome when evaluated at as early as 1 or 2 years of life. ${ }^{1-5}$ Patients with deletion 22q11.2 (del22q11.2) may have worse motor and neurologic development than other children after CCS. ${ }^{6-8} \mathrm{~A}$ large singleinstitution study investigating the neurodevelopment of 5-year-old children after earlier repair or palliation of CHD showed that lower socioeconomic status and del22q11.2 were associated with significantly lower full-scale intelligence quotient (IQ) scores. ${ }^{6}$ Maharasingam and associates ${ }^{7}$ compared the neurodevelopmental status of 10 children (mean age 3.6 years) with del22q11.2 with 20 matched controls, both after cardiac surgery in the first year of life. Using the Ruth Griffiths test, they found a lower developmental quotient in the del22q11.2 group. ${ }^{7}$ Swillen and colleagues ${ }^{8}$ evaluated 11 children (mean age 41 months) with del22q11.2 and 


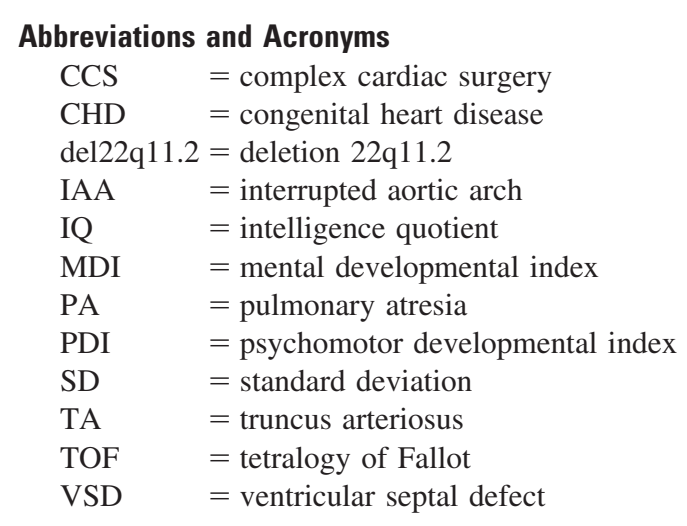

conotruncal defects repaired in the first year of life, showing significant fine and gross motor delay when compared with children with the same types of conotruncal defects.

There are no reports of which we are aware evaluating the neurodevelopmental outcome after neonatal CCS in patients with and without del22q11.2. Therefore, we sought to compare the general and neurodevelopmental outcomes at 18 to 24 months between subjects with and without del22q11.2 who underwent neonatal ( $\leq 6$ weeks of age) CCS for CHD at the same institution.

\section{Patients and Methods}

This is a case-comparison within cohort study using data from an interprovincial inception cohort outcomes study conducted in three provinces in Western Canada. As previously described, ${ }^{4,5}$ from September 1996 through August 31, 2004, infants 6 weeks of age or younger were identified at the time of CCS. Surgery was performed at the Stollery Children's Hospital, Edmonton, Alberta, Canada.

Preoperative, intraoperative, and postoperative variables that were previously agreed on were collected prospectively. ${ }^{4,5}$ Longterm follow-up was discussed with parents or guardians once survival was probable, and with their consent, contact was made with their respective follow-up clinics at the tertiary site of origin.

\section{Subjects}

All consecutive patients with del22q11.2 identified over the 8-year period were registered (group 1). A comparison group of patients matched for type of CHD, socioeconomic status, and year of operation were identified (group 2). The inclusion criteria were as follows: (1) CCS (requiring use of cardiopulmonary bypass) at the Stollery Children's Hospital, (2) CCS performed from September 1996 to August 31, 2004, and (3) CCS at 6 weeks of age or less. The exclusion criteria were as follows: (1) chromosomal anomalies or syndromes other than del22q11.2 and (2) CHD surgery not requiring cardiopulmonary bypass. All patients in group 1 had the del22q11.2 confirmed by either DNA analysis or fluorescence in situ hybridization using standard probes., ${ }^{9,10}$ All patients in the comparison group had a normal karyotype and DNA analysis. All survivors received multidisciplinary neurodevelopmental assess- ments through existing neonatal follow-up clinics in Edmonton and Calgary, Alberta; Regina and Saskatoon, Saskatchewan; and Winnipeg, Manitoba. Ethics board approvals were obtained from each site before the onset of the study. All parents or guardians signed individual consent forms.

\section{Early Childhood Assessments}

Outcomes assessment was completed at 18 to 24 months of age. At assessment, a research nurse recorded history of hospitalizations, illnesses, medication use, and need for supplemental oxygen. Physical measurements were obtained as have been described., The family socioeconomic status was determined by the Blishen Index, a formula considering the relative income, needed education, and prestige factor of employment with a population mean and standard deviation (SD) of 43 (13). ${ }^{11}$ Maternal education was indicated by years of schooling. Pediatricians experienced in neurodevelopmental follow-up examined each child for evidence of cerebral palsy ${ }^{12}$ or visual impairment defined as corrected visual acuity in the better eye of less than 20/60. ${ }^{4,5}$ Hearing was evaluated by experienced certified pediatric audiologists in soundproof environments as has been described. ${ }^{4,5}$ Hearing impairment was defined as binaural sensorineural hearing loss of more than $40 \mathrm{~dB}$ at any frequency from 250 to $4000 \mathrm{~Hz}$. Certified pediatric psychologists and psychometrists administered the Bayley Scales of Infant Development II, ${ }^{13}$ a widely accepted standardized outcome measure used in neonatal follow-up clinics yielding separate mental (MDI) and psychomotor developmental index (PDI) standardized scores with a mean of 100 and an SD of 15. Developmental indices of less than 70 (2 SD below the mean) indicated mental or motor delay. Within a normative sample, $2.27 \%$ of children have scores of less than 70. Behavioral indices were also recorded with percentiles at or below 10 considered as nonoptimal scores.

\section{Statistics}

Demographic variables included gestational age, birth weight, gender, prenatal diagnosis, race, year of operation, socioeconomic status, mother's year of schooling, guardianship, home location, and out-of-region referral. Preoperative variables included cardiac diagnoses, cardiopulmonary resuscitation, seizure, highest plasma lactate, and lowest $\mathrm{pH}$ and arterial oxygen tension. Intraoperative variables included cardiopulmonary bypass time, aortic crossclamp time, deep hypothermic circulatory arrest use and time, and need for reinstitution of bypass in the operating room. Postoperative variables included highest plasma lactate on day 1 and days 2 to 5 , seizure, extracorporeal life support, cardiopulmonary resuscitation, duration of postoperative ventilation, and overall duration of ventilation and hospitalization. The primary outcomes of interest were the neurodevelopmental indices obtained from the Bayley Scales of Infant Development II (MDI and PDI). The secondary outcomes included mortality and morbidity. Morbidity was defined by the health and growth variables, which included height, weight, head circumference, number of cardiac and noncardiac hospitalizations, number of illnesses requiring a physician's care, number of specialist physicians involved in the care, specialized care required, use of oxygen, special diet, or gastrostomy tube, long-term cardiac or pulmonary medication, and pacemaker use.

For comparison of the two matched groups, before deaths, the paired-samples $t$ test and Wilcoxon 2-related samples test for 
continuous data and the McNemar test for dichotomous variables were used. Descriptive variables for surviving subjects were analyzed by the univariate $t$ test, $\chi^{2}$ test, and Fisher exact test (2-sided) analyses. Bonferonni correction was applied. Sequential stepwise multiple regression for variables from each of the stages (preoperative, operative, postoperative) were used to explore the overall greatest proportion of developmental outcome explained by a combination of predictors to a significance level of .05. SPSS (SPSS, Inc, Chicago, Ill) version 12.0 for Windows was used for analyses.

\section{Results}

\section{Description of Cohort}

There were 16 patients in each group. Complete follow-up data were available for all patients. The groups were well matched. Each group comprised 6 (37.5\%) patients with interrupted aortic arch (IAA), 6 (37.5\%) patients with truncus arteriosus (TA), and 4 (25\%) patients with tetralogy of Fallot (TOF). Ten patients had IAA type B (IAA-B) and 2 (both in group 2) had type A (IAA-A). The socioeconomic status was 43.9 (15.2) and 39.4 (11.2) in group 1 and group 2 , respectively $(P=$ not significant). The year of surgery was 2000.6 (2.8) and 2001.1 (2.2) in group 1 and group 2, respectively $(P=$ not significant). In addition, demographic, preoperative, operative, and postoperative variables showed no statistically significant differences between the two groups when comparing the entire cohort. Only 1 patient (group 2) required extracorporeal life support postoperatively. Only 1 patient in each group required preoperative ventilation. Only 2 patients had preoperative convulsions, both in group 1 , and they both died.

\section{Secondary Outcomes}

Three patients (1 with IAA-B and 2 with TOF) in group 1 and 1 (TA) in group 2 died, for mortality rates of $19 \%(3 / 16)$ and $6 \%(1 / 16)$, respectively $(P=.60)$. Of the 4 deaths, the etiology was cardiac in 2, respiratory in 1 , and unknown in 1 .

Demographic, preoperative, operative, and postoperative variables were compared between survivors in group $1(\mathrm{n}=$ 13) and group $2(n=15)$ and showed no statistically significant differences (Table 1). Health and growth outcomes among survivors are shown in Table 2. Use of long-term pulmonary medications was significantly different $(P \leq .005)$, with $6(46 \%)$ of 13 patients in group 1 and $0(0 \%)$ of 15 in group 2 requiring these medications at follow-up. There were no subjects in either group with cerebral palsy or visual or sensorineural hearing disabilities.

\section{Primary Outcomes}

Follow-up was achieved in all survivors and performed at a mean age of 22 (4) months. The average MDI (66.1 [10.6] vs 86.3 [14.6], $t$ test $=-4.129, P<.001)$ and PDI (55.0 [9.4] vs 82.3 [14.3], $t$ test $=-5.872, P<.001)$ scores were significantly lower in group 1 than in group 2 (Figure 1). Mental delay (MDI $<70$ ) occurred in $8(61.5 \%)$ of 13 in group 1 compared with $2(13.8 \%)$ of 15 in group $2(P=$ $.016)$ (Table 3). Psychomotor delay (PDI $<70$ ) occurred in $11(84.6 \%)$ of 13 in group 1 and $1(6.7 \%)$ of 15 in group 2 $(P<.001)$ (Table 3). Of the 2 patients in group 2 with mental delay, 1 had dehydration and shock resulting from a Rotavirus gastrointestinal illness in infancy, and the other was the only patient requiring postoperative extracorporeal life support. Mental and/or psychomotor delay occurred in $12(92 \%)$ of 13 in group 1 and $2(13 \%)$ of 15 in group 2 $(P<.001)$ (Table 3). Almost all $(12 / 13)$ children with del22q11.2 had poor motor quality for age (Table 3 ).

We compared demographic, preoperative, intraoperative, and postoperative variables between patients with and without mental and/or psychomotor delay and found no statistically significant differences except for the del22q11.2 diagnosis: $1(7.1 \%)$ of 14 patients without delay and 12 (85.7\%) of 14 patients with delay (Fisher exact test, $P<$ .001). All demographic, preoperative, intraoperative, and postoperative variables were examined for their correlation with MDI and PDI scores. The variables with correlation at $P \leq 0.1$ (Table 4) were entered into stepwise multiple regression analyses. The del22q11.2 diagnosis accounted for $27 \%$ of the variability in MDI score (adjusted $r^{2}=.274$, $P=.003$ ), and $61 \%$ of the variability in PDI scores (adjusted $r^{2}=.613, P<.001$ ). No other variable was significant in the stepwise multiple regression analyses.

\section{Discussion}

To our knowledge, this is the first report describing the 18to 24-month neurodevelopmental outcomes of patients with del22q11.2 identified as neonates requiring CCS. All del22q11.2 patients had neonatal CCS and were compared with patients without del22q11.2 having neonatal CCS, being matched for cardiac lesion, year of operation, and socioeconomic status. We found that these neonates with del22q11.2 have a high risk for compromised neurodevelopmental outcome on follow-up, characterized by significantly lower MDI and PDI scores and significantly higher rates of motor and mental delay than in the matched comparison group (Figure 1, Table 3). We compared demographic, preoperative, intraoperative, and postoperative variables between the del22q11.2 group and comparison group and found no significant differences (Table 1). These variables were also compared between patients with and without delay, and no differences were detected except for the diagnosis of del22q11.2. Moreover, stepwise multiple regression analyses found that del22q11.2 accounted for a significant portion of the variability in MDI and PDI scores. These results corroborate and complement the limited published data showing lower developmental quotient and 
TABLE 1. Descriptive variables of 13 survivors with del22q11.2 and CCS at $\leq 6$ weeks of age (group 1 ) and 15 comparison subjects (group 2)

\begin{tabular}{|c|c|c|c|c|c|}
\hline & \multirow[b]{2}{*}{ Total $(\mathbf{n}=\mathbf{2 8})$} & \multicolumn{2}{|c|}{ Subjects } & \multirow{2}{*}{$\begin{array}{c}\chi^{2}, t \text { test, Fisher } \\
\text { exact test }{ }^{*}\end{array}$} & \multirow[b]{2}{*}{$P$ value } \\
\hline & & Group $1(n=13)$ & Group $2(n=15)$ & & \\
\hline \multicolumn{6}{|l|}{ Demographic/preoperative } \\
\hline Socioeconomic status & $41.3(13.9)$ & $45.1(15.9)$ & $38.1(11.5)$ & 1.3248 & .189 \\
\hline Mother's years of schooling & $13.0(1.8)$ & $13.5(1.8)$ & $12.7(1.8)$ & 1.163 & .255 \\
\hline Guardianship: both parents & $25(92.8 \%)$ & $13(100 \%)$ & $12(80 \%)$ & - & .562 \\
\hline Race: white & $24(85.7 \%)$ & $11(84.6 \%)$ & $13(86.7 \%)$ & - & .999 \\
\hline Location of home: large urban & $17(60.7 \%)$ & $7(53.8 \%)$ & $10(66.7 \%)$ & - & 692 \\
\hline Referral from out of region & $15(53.6 \%)$ & $7(53.8 \%)$ & $8(53.3 \%)$ & - & .999 \\
\hline Sex: male & $18(64.3 \%)$ & $8(61.5 \%)$ & $10(66.7 \%)$ & - & .999 \\
\hline Gestational age: wk & $38.9(2.2)$ & $38.5(2.9)$ & $39.2(1.5)$ & .749 & .464 \\
\hline Birth weight: g & $3202(725)$ & $3145(844)$ & $3252(629)$ & .382 & .705 \\
\hline \multicolumn{6}{|l|}{ Major cardiac diagnosis } \\
\hline Interrupted aortic arch & & & & 2.037 & .361 \\
\hline Type B & $9(32.1 \%)$ & $5(38.5 \%)$ & $4(26.7 \%)$ & & \\
\hline Type A & $2(7.1 \%)$ & $0(0 \%)$ & $2(13.3 \%)$ & & \\
\hline Truncus arteriosus & $11(39.4 \%)$ & $6(46.2 \%)$ & $5(33.3 \%)$ & - & .700 \\
\hline Tetralogy of Fallot & $6(21.4 \%)$ & $2(15.4 \%)$ & $4(26.7 \%)$ & - & .655 \\
\hline Cardiorespiratory arrest & $1(3.6 \%)$ & $0(0 \%)$ & $1(6.7 \%)$ & - & .999 \\
\hline Convulsions & 0 & 0 & 0 & & \\
\hline Highest plasma lactate (mmol/L) & $3.1(5.1)$ & $2.1(.7)$ & $4.1(6.9)$ & -1.107 & .286 \\
\hline Lowest arterial pH & $7.33(.09)$ & $7.32(.07)$ & $7.33(.11)$ & -.262 & .795 \\
\hline Lowest $\mathrm{PaO}_{2}(\mathrm{~mm} \mathrm{Hg})$ & $55.3(21.9)$ & $50.1(20.7)$ & $59.9(22.5)$ & -1.192 & .244 \\
\hline No. of children ventilated & $2(7.1 \%)$ & $1(7.7 \%)$ & $1(6.7 \%)$ & - & .999 \\
\hline \multicolumn{6}{|l|}{ Intraoperative } \\
\hline CPB (min) & $116.1(40.1)$ & $110.2(34.8)$ & $121.2(44.8)$ & -.719 & .498 \\
\hline Aortic crossclamp time (min) & $56.4(26.4)$ & $49.3(22.3)$ & $62.5(28.9)$ & -1.340 & .192 \\
\hline DHCA used & $16(57.1 \%)$ & $8(61.5 \%)$ & $8(53.3 \%)$ & - & .942 \\
\hline DHCA time $(n=16)(\min )$ & $44.6(17.1)$ & $43.0(22.8)$ & $46.1(10.1)$ & .355 & .730 \\
\hline Need for re-CPB in $\mathrm{OR}$ & $3(10.7 \%)$ & $1(7.7 \%)$ & $2(13.3 \%)$ & - & .999 \\
\hline \multicolumn{6}{|l|}{ Postoperative } \\
\hline Highest plasma lactate, day 1 & $5.9(3.5)$ & $5.0(3.0)$ & $6.7(3.9)$ & -1.361 & .186 \\
\hline Highest plasma lactate, day 2 to 5 & $2.7(1.4)$ & $2.8(1.2)$ & $2.6(1.6)$ & .499 & .622 \\
\hline Seizures & $3(10.7 \%)$ & $2(15.3 \%)$ & $1(6.7 \%)$ & - & .899 \\
\hline ECLS & $1(3.6 \%)$ & $0(0 \%)$ & $1(6.7 \%)$ & - & .999 \\
\hline Cardiopulmonary resuscitation & $1(3.6 \%)$ & $0(0 \%)$ & $1(6.7 \%)$ & - & .999 \\
\hline \multicolumn{6}{|l|}{ Overall } \\
\hline Duration of ventilation & $17.3(30.6)$ & $16.6(20.5)$ & $17.9(37.9)$ & .286 & .777 \\
\hline Duration of hospitalization & $36.1(46.4)$ & $38.9(40.5)$ & $33.7(52.3)$ & -.106 & .916 \\
\hline
\end{tabular}

del22q11.2, Deletion 22q11.2; CCS, complex cardiac surgery; $C P B$, cardiopulmonary bypass; $D H C A$, deep hypothermic circulatory arrest; $O R$, operating room; $E C L S$, extracorporeal life support; Values are mean (SD) or $\mathrm{n}(\%) .{ }^{*} \chi^{2}$ Analysis, Student $t$ test, Fisher exact test.

scores, significant motor delay, and lower IQ scores for del22q11.2 patients compared with other children with surgically repaired $\mathrm{CHD}^{6-8}$

Chromosome 22q11.2 deletion (del22q11.2) is the most common known genetic microdeletion syndrome. Its prevalence is estimated at 1 per 3000 to 6000 in the general population. ${ }^{14,15}$ The presentation of del22q11.2 lies along a wide phenotypic spectrum including more than 180 features, with the most common phenotypes being CHD, hypocalcemia, immunodeficiency, facial dysmorphisms, palatal abnormalities, velopharyngeal dysfunction, and neu- rologic, behavioral, and developmental disorders. ${ }^{16} \mathrm{CHD}$ is the most common structural anomaly in patients with del22q11.2, affecting up to $70 \%$ to $80 \% .{ }^{14,15,17}$ A population-based study ${ }^{14}$ and studies looking at the prenatal ${ }^{18,19}$ and postnatal ${ }^{20,21}$ prevalence of the most common conotruncal congenital heart defects have revealed consistent findings. ${ }^{14,18-21}$ Del22q11.2 is found in up to $50 \%$ of patients with IAA, $20 \%$ to $30 \%$ with TA, $12 \%$ to $20 \%$ with TOF, and $20 \%$ to $30 \%$ with pulmonary atresia and ventricular septal defect (PA-VSD). ${ }^{14,18-21}$ That del22q11.2 is this common adds to the significance of our findings. 
TABLE 2. Health and growth outcomes of 13 children aged 18 to 24 months with del22q11.2 (group 1) and 15 comparison matched survivors (group 2)

\begin{tabular}{|c|c|c|c|c|c|}
\hline & \multirow[b]{2}{*}{ Total $(n=28)$} & \multicolumn{2}{|c|}{ Subjects } & \multirow{2}{*}{$\begin{array}{l}\chi^{2}, t \text { test, Fisher } \\
\text { exact test }{ }^{*}\end{array}$} & \multirow[b]{2}{*}{$P$ value } \\
\hline & & Group 1 (n = 13) & Group 2 (n = 15) & & \\
\hline No. of hospitalizations for illness not related to heart & $3.6(7.1)$ & $4.2(6.6)$ & $3.1(7.8)$ & 0.395 & .696 \\
\hline No. of hospitalizations related to heart & $.25(.6)$ & $0.0(0.0)$ & $0.47(0.7)$ & -2.432 & .029 \\
\hline No. of other illnesses requiring doctor's care (not check-up) & $4.8(6.4)$ & $6(7.7)$ & $3.8(4.9)$ & 0.908 & .372 \\
\hline $\begin{array}{l}\text { No. of specialists currently seen excluding primary care } \\
\text { physicians }\end{array}$ & $2.4(1.4)$ & $2.9(1.6)$ & $1.9(1.2)$ & 1.886 & .070 \\
\hline \multicolumn{6}{|l|}{ Specialized care } \\
\hline Regular pulmonary specialist for asthma, aspiration, reflux & 9 & 7 & 2 & Not computed & \\
\hline Myringotomies & 4 & 4 & 0 & & \\
\hline Cleft palate repair & 3 & 2 & 1 & & \\
\hline Tracheostomy & 1 & 1 & 0 & & \\
\hline Left vocal cord paralysis & 7 & 3 & 4 & & \\
\hline Current use of supplemental oxygen & $2(7.1 \%)$ & $2(15.4 \%)$ & $0(0 \%)$ & - & .206 \\
\hline Current use of special or supplemental diet & $12(42.9) \%$ & $6(53.8 \%)$ & $6(40 \%)$ & - & .486 \\
\hline Current use of gastrostomy & $6(21.4 \%)$ & $3(23.1 \%)$ & $3(20 \%)$ & - & .928 \\
\hline Medically fragile† & $3(10.7 \%)$ & $3(23.1 \%)$ & $0(0 \%)$ & - & .087 \\
\hline Chronic pulmonary medication & $6(21.4 \%)$ & $6(46.2 \%)$ & $0(0 \%)$ & - & .005 \\
\hline Chronic cardiac medication & $3(10.7 \%)$ & $1(7.7 \%)$ & $2(13.3 \%)$ & - & .999 \\
\hline Pacemaker & $3(10.7 \%)$ & $0(0 \%)$ & $3(20 \%)$ & - & .226 \\
\hline Length $<$ third percentile & $4(14.3 \%)$ & $4(30.8 \%)$ & $0(0 \%)$ & - & .035 \\
\hline Weight $<$ third percentile & $2(7.1 \%)$ & $1(7.7 \%)$ & $1(6.7 \%)$ & - & .999 \\
\hline Microcephaly & $2(7.1 \%)$ & $2(15.4 \%)$ & $0(0 \%)$ & - & .510 \\
\hline
\end{tabular}

Values are mean (SD) or $\mathrm{n}(\%) .{ }^{*} \chi^{2}$ Analysis, Student $t$ test, Fisher exact test. †Medically fragile-long-term hospitalization or in-home nursing care. After Bonferonni correction, a $P$ value of $\leq .005$ would be considered significant.

As in our study, neurodevelopmental abnormalities in cohorts of children with del22q11.2 have been found by other authors. Motor disability and delay in acquisition of motor skills in del22q11.2 patients of different age groups have been documented by some investigators. ${ }^{2,8,22,23}$ The etiology of the psychomotor delay in this patient population is unclear. Hypotonia may be a contributing factor to the development of motor delay. Mental delay has also been shown among del22q11.2 patients of different pediatric age groups. Gerdes and colleagues, ${ }^{22,23}$ in 2 studies of patients referred to their genetic center, showed that preschool children with del22q11.2 have mild-to-moderate developmental delay, mild hypotonia, and language and speech delay. Their patients assessed at ages 12 to 42 months with the Bayley Scales of Infant Development II had mean MDI and PDI scores of 69.8 (15) and 60.1 (12), respectively. ${ }^{22}$ They reported a $46.4 \%$ incidence of mental delay (MDI $<70$ ) and $79 \%$ for motor delay (PDI $<70$ ). ${ }^{22}$ In a subsequent article with a larger patient number accumulated, the incidence of mental delay (MDI < 70) in toddlers was $58 \%{ }^{23}$ When comparing nonmatched patients with $(\mathrm{n}=29)$ and without CHD ( $\mathrm{n}=11)$, they found no difference in MDI mean scores $(66.6[18]$ vs $71[14]) .^{22}$ Niklasson and colleagues ${ }^{24}$ examined 30 children with del22q11.2 aged 7 to 13 years and showed a high incidence of attention deficit hyperac- tivity disorder (mainly the inattentive type) and nonverbal learning disability. Del22q11.2 patients are also at higher risk for the development of schizophrenia. ${ }^{15}$ The association of del22q11.2 cognitive deficits with brain structural abnormalities has been suggested. ${ }^{25,26}$

Del22q11.2 has been suggested to be a risk factor for increased mortality after repair of conotruncal CHD. In a 5 -year prospective multicenter study, Anaclerio and colleagues $^{27}$ showed that among patients with conotruncal defects, del22q11.2 was a risk factor for higher surgical mortality in children with PA-VSD and IAA, but not in those with TOF or TA. Mahle and colleagues ${ }^{21}$ demonstrated that the 5-year survival after surgical repair of PAVSD was lower in patients affected by del22q11.2 (36\% vs $90 \%$ in those without del22q11.2, $P=.001$ ). In contrast, another study did not detect any difference in morbidity or mortality between patients with and without del22q11.2 after cardiac surgery. ${ }^{28}$ In our study, owing to the small number of patients, we did not have enough power to test for difference in mortality and hence could not confirm or refute the previous studies.

Some literature suggests that genetic counseling in del22q11.2 is a difficult task, for the syndrome carries unpredictable variability in its phenotypic presentation, including neurodevelopmental profile. Our data may allow for 

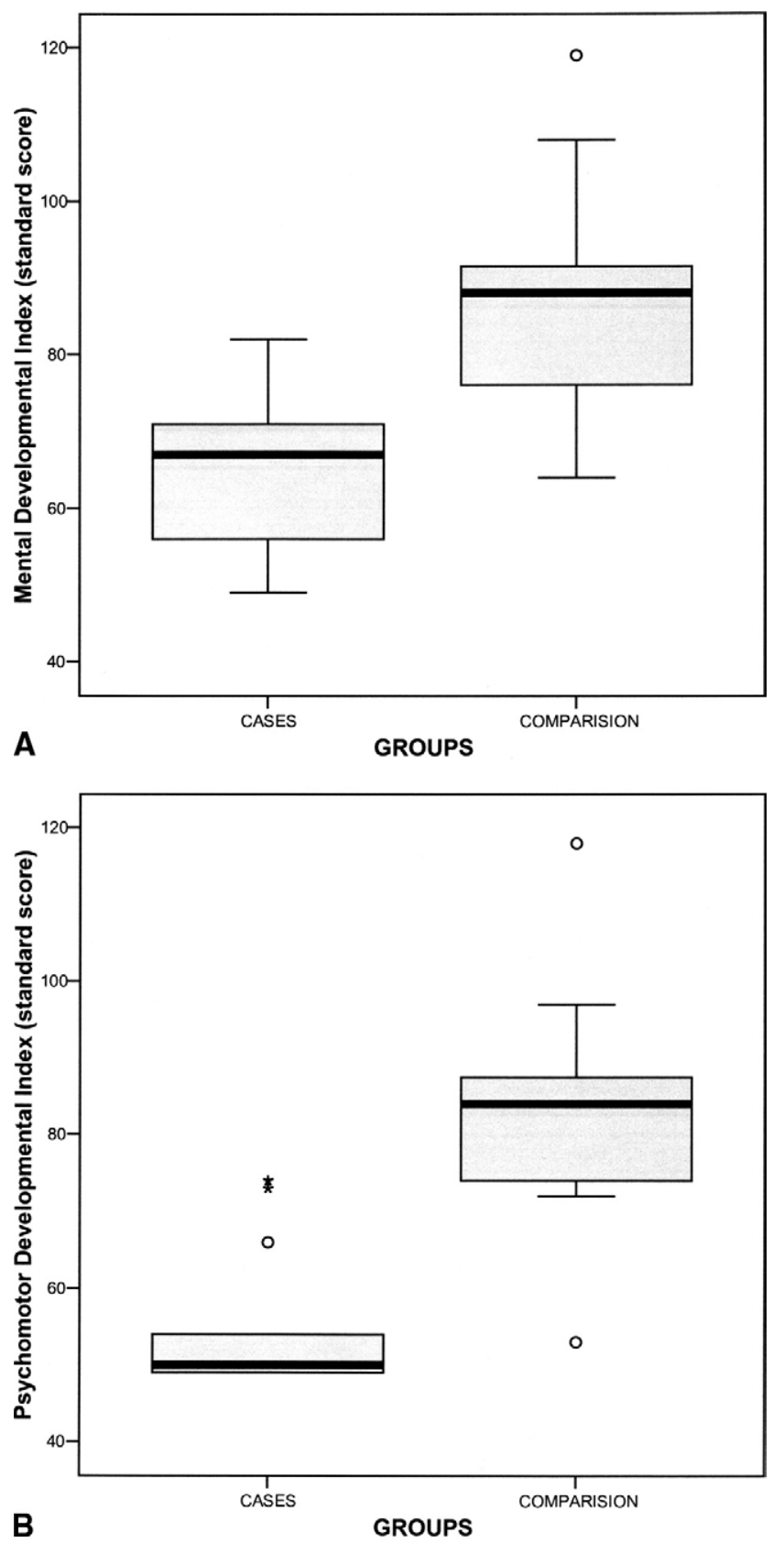

Figure 1. A, Mental developmental index in survivors with del22q11.2 ( $n=13$, group 1 ) and a comparison group $(n=15$, group 2). B, Psychomotor developmental index in survivors with del22q11.2 ( $n=13$, group 1 ) and comparison group $(n=15$, group 2). The thick line inside the box represents the median, the box is formed of the first to the third quartiles $(25 \%$ and $75 \%$ ), with the whiskers extending to the minimum and maximum value that is not considered an outlier. The circles and stars represent outliers (more than 1.5 times the interquartile range from the first and third quartiles). more guided and informed antenatal and postnatal counseling to families with neonates affected by the chromosome 22q11.2 deletion syndrome who require neonatal CCS. In addition, considering the long-term medical and neurobehavioral outcomes, some argue that parents with a fetal diagnosis of CHD possibly associated with 22q11.2 deletion, such as conotruncal anomalies, should be offered the option of prenatal screening for del22q11.2. ${ }^{29}$ Furthermore, early intervention may be instrumental in helping this specific patient population to optimize neurologic and physical developmental potential and hence level of functioning in society. This need for early intervention has previously been emphasized. ${ }^{22,23}$ In our cohort, 9 (69\%) of the 13 del22q11.2 patients received developmental intervention compared with $3(20 \%)$ of 15 in the comparison group $(P=.027)$.

The contribution of del22q11.2 to the delay of these children after CCS requires further evaluation. By approaching this question from a perspective of a casecomparison study, we have shown scores below normative values for both study groups. For young children after CCS for IAA, TA, and TOF in the neonatal period, but without chromosomal abnormalities, the proportion with mental delay is 6 times larger and the proportion with motor delay is 3 times larger than that seen in a normative sample. This article does not explore all of the operative and perioperative reasons for this delay, but, as we have reported previously, ${ }^{4}$ it does show that these children without chromosomal abnormalities have some developmental concerns. However, this article also shows that the children with del22q11.2 after neonatal CCS and otherwise matched to the comparison children have significantly lower scores than the matched group, with the proportion with mental delay 27 times larger and the proportion with motor delay 37 times larger than that in a normative sample.

Using sequential stepwise multiple regression, we attempted to address the question of the proportion of outcome contributed to by CCS for those with del22q11.2. We found that $27 \%$ of the variability of the mental scores and $61 \%$ of the variability of the motor scores in the combined cohort are explained by the chromosomal abnormality. This leaves $73 \%$ of mental and 39\% of motor scores' variability unexplained by this study. In addition to the CCS variables, causes that could relate to delay among the del22q11.2 group include ongoing childhood illness, more common in this group. This study is not designed to evaluate other types of surgery for children with del22q11.2, and it gives no indication that a change in surgical approach should be considered. The study supports the concept that children with del22q11.2 do less well than matched comparison children under the same clinical conditions and that motor scores and motor quality are at greatest risk. It should be noted that the mean mental score of the del22q11.2 children 
TABLE 3. Neurodevelopmental outcomes of 13 survivors aged 18 to 24 months with del22q11.2 (group 1) and 15 comparison matched survivors (group 2)

\begin{tabular}{lcccr}
\hline & & \multicolumn{2}{c}{ Subjects } & \\
\cline { 3 - 4 } & Total $\mathbf{n}=\mathbf{2 8})$ & Group 1 (n= 13) & Group 2 (n = 15) & $\boldsymbol{P}$ value \\
\hline Mental delay (MDI $<70)$ & $10(35.7 \%)$ & $8(61.5 \%)$ & $2(13.8 \%)$ & .016 \\
Psychomotor delay (PDI $<70)$ & $12(42.9 \%)$ & $11(84.6 \%)$ & $1(6.7 \%)$ & $<.001$ \\
Mental and/or psychomotor delay (MDI or PDI $<70)$ & $14(50.0 \%)$ & $12(92.3 \%)$ & $2(13.3 \%)$ & $<.001$ \\
Behavioral indices, No. with nonoptimal scores $(\leq 10$ th percentile) & & & & .999 \\
$\quad$ Orientation/engagement & $2(7.2 \%)$ & $1(7.7 \%)$ & $1(6.7 \%)$ & .920 \\
Emotional regulation & $1(3.6 \%)$ & $1(7.7 \%)$ & $0(0 \%)$ & $<.001$ \\
Motor quality & $12(42.8 \%)$ & $12(92.3 \%)$ & $0(0 \%)$ & .583 \\
$\quad$ Total score & $3(10.4 \%)$ & $2(15.4 \%)$ & $1(6.7 \%)$ & .027 \\
Developmental intervention & $12(42.9 \%)$ & $9(69 \%)$ & $3(20 \%)$ & \\
\hline
\end{tabular}

MDI, Mental developmental index; PDI, psychomotor developmental index. Values are mean (SD) or $\mathrm{n}(\%)$.

in this study is 66.1 , almost identical to that of the children reported on by Gerdes and associates, ${ }^{22}$ where the mean score was 66.6 for those with CHD.

A limitation of this study is the small number of patients despite the 8-year surgical period and the high yearly surgical volumes. It is not possible to assess whether this number is representative of the expected incidence of del22q11.2 in the general population because we studied a selective cohort of neonates with CHD. In addition, the rate of termination of fetuses with an antenatal diagnosis of del22q11.2 and CHD is unknown. The small number of study patients did not allow subgroup analysis of the different cardiac lesions. Finally, the restricted selection of patients undergoing CCS at 6 weeks of age or less accounts for the different distribution of the cardiac phenotypes in our series compared with others. ${ }^{14,18-21}$ Nevertheless, to our knowledge, this is the largest cohort of patients with del22q11.2 identified as neonates requiring CCS and with prospective follow-up data.

\section{Conclusions}

Neonates with chromosome 22q11.2 deletion who undergo neonatal CCS have a significantly worse neurodevelopmen-

TABLE 4. Pearson product moment correlations with $\boldsymbol{P} \leq$ .1 of mental and motor developmental levels and potentially modifiable variables among 28 children ages 18 to 24 months surviving after complex cardiac surgery at $\leq 6$ weeks of age*

\begin{tabular}{lcccccc}
\hline & \multicolumn{2}{c}{ MDI } & & \multicolumn{2}{c}{ PDI } \\
\cline { 2 - 3 } \cline { 5 - 6 } & \multicolumn{1}{c}{$\boldsymbol{r}$} & $\boldsymbol{P}$ value & & $\boldsymbol{r}$ & \multicolumn{1}{c}{$\boldsymbol{P}$ value } \\
\hline Preoperative lowest $\mathrm{PaO}_{2}$ & - & - & & 0.411 & .030 \\
Days in hospital & -.348 & .070 & & -0.344 & .082 \\
Days ventilated & - & - & & -0.325 & .092 \\
del22q11.2 & -.548 & .003 & & -0.792 & .000
\end{tabular}

MDI, Mental developmental index; PDI, psychomotor developmental index. *There were 13 children with del22q11.2 and 15 comparison children. tal outcome when evaluated at 18 to 24 months of age compared with a matched group without del22q11.2. This adverse neurodevelopmental outcome is characterized by significantly lower MDI and PDI scores and significantly higher rates of motor and mental delay. This information suggests that the adverse outcomes for those with del22q11.2 are strongly associated with the chromosomal abnormality and are associated to a lesser extent with the neonatal cardiac surgery and associated events. This information should allow more informed antenatal and postnatal counseling. Early targeted medical and rehabilitation intervention through a dedicated multidisciplinary approach is instrumental for this fragile and at-risk patient population.

We thank the families of these children for their active participation in the developmental sites across Western Canada and their commitment to this project. We sincerely thank the research coordinators who made this research possible: H. Christianson and D. Anseeuw-Deeks, Calgary, Alberta; V. Debooy, Winnipeg, Manitoba; T. Martindale, Saskatoon, Saskatchewan; and G. Alton and L. Sanders, Edmonton, Alberta.

\section{References}

1. Wernovsky G, Shillingford AJ, Gaynor JW. Central nervous system outcomes in children with complex congenital heart disease. Curr Opin Cardiol. 2005;20:90-4.

2. Dittrich H, Buhrer C, Grimmer I, Dittrich S, Abdul-Khaliq H, Lange PE. Neurodevelopment at 1 year of age in infants with congenital heart disease. Heart. 2003;89:436-41.

3. Robertson DR, Justo RN, Burke CJ, Pohlner PG, Graham PL, Colditz PB. Perioperative predictors of developmental outcome following cardiac surgery in infancy. Cardiol Young. 2004;14:389-95.

4. Robertson CM, Joffe AR, Sauve RS, Rebeyka IM, Phillipos EZ, Dyck $\mathrm{JD}$, et al. Outcomes from an interprovincial program of newborn open heart surgery. J Pediatr. 2004;144:86-92.

5. Freed DH, Robertson CMT, Sauve RS, Joffe AR, Rebeyka IM, Ross $\mathrm{DB}$, et al. Intermediate-term outcomes of the arterial switch operation for transposition of the great arteries in neonates: alive but well? $J$ Thorac Cardiovasc Surg. 2006;132:845-52.

6. Forbess JM, Visconti KJ, Hancock-Friesen C, Howe RC, Bellinger DC, Jonas RA. Neurodevelopmental outcome after congenital heart surgery: results from an institutional registry. Circulation. 2002; 106(12 Suppl 1):I95-102. 
7. Maharasingam M, Ostman-Smith I, Pike MG. A cohort study of neurodevelopmental outcome in children with DiGeorge syndrome following cardiac surgery. Arch Dis Child. 2003;88:61-4.

8. Swillen A, Feys H, Adriaens T, Nelissen L, Mertens L, Gewillig M, et al. Early motor development in young children with 22q11 deletion syndrome and a conotruncal heart defect. Dev Med Child Neurol. 2005; 47:797-802.

9. Yobb TM, Somerville MJ, Willatt L, Firth HV, Harrison K, MacKenzie J, et al. Microduplication and triplication of 22q11.2: a highly variable syndrome. Am J Hum Genet. 2005;76:865-76.

10. Carey AH, Kelly D, Halford S, Wadey R, Wilson D, Goodship J, et al. Molecular genetic study of the frequency of monosomy 22q11 in DiGeorge syndrome. Am J Hum Genet. 1992;51:964-70.

11. Blishen BR. The 1981 Socioeconomic Index for Occupations in Canada. Can Rev Soc Anth. 1987;24:465-88.

12. Bax MCO. Terminology and classifications of cerebral palsy. Dev Med Child Neurol.1964;6:259-97.

13. Bayley N. Manual: Bayley Scales of Infant Development. 2nd ed. Psychological Corp; San Antonio: 1993.

14. Botto LD, May K, Fernhoff PM, Correa A, Coleman K, Rasmussen $\mathrm{SA}$, et al. A population-based study of the 22q11.2 deletion: phenotype, incidence, and contribution to major birth defects in the population. Pediatrics. 2003;112(1Pt1):101-107.

15. Perez E, Sullivan KE. Chromosome 22q11.2 deletion syndrome (DiGeorge and velocardiofacial syndromes). Curr Opin Pediatr. 2002;14: 678-83.

16. Robin NH, Shprintzen RJ. Defining the clinical spectrum of deletion 22q11.2. J Pediatr. 2005;47:90-6.

17. Marino B, Digilio MC, Toscano A, Giannotti A, Dallapiccla B. Congenital heart defects in patients with DiGeorge/velocardiofacial syndrome and del22q11. Genet Couns. 1999;10:25-33.

18. Boudjemline Y, Fermont L, Le Bidois J, Lyonnet S, Sidi D, Bonnet D. Prevalence of 22q11 deletion in fetuses with conotruncal cardiac defects: a 6-year prospective study. J Pediatr. 2001;138:520-4.

19. Volpe P, Paladini D, Marasini M, Buonadonna AL, Russo MG, Caruso $\mathrm{G}$, et al. Common arterial trunk in the fetus: characteristics, associa- tions, and outcome in a multicentre series of 23 cases. Heart. 2003; 89:1437-41.

20. Goldmuntz E, Clark BJ, Mitchell LE, Jawad AF, Cuneo BF, Reed L, et al. Frequency of $22 \mathrm{q} 11$ deletions in patients with conotruncal defects. J Am Coll Cardiol. 1998;32:492-8.

21. Mahle WT, Crisalli J, Coleman K, Campbell RM, Tam VK, Vincent $\mathrm{RN}$, et al. Deletion of chromosome 22q11.2 and outcome in patients with pulmonary atresia and ventricular septal defect. Ann Thorac Surg. 2003;76:567-71.

22. Gerdes M, Solot C, Wang PP, Moss E, LaRossa D, Randall P, et al. Cognitive and behavioral profile of preschool children with chromosome 22q11.2 deletion. Am J Med Genet. 1999;85:127-33.

23. Gerdes M, Solot C, Wang PP, McDonald-McGinn DM, Zackai EH. Taking advantage of early diagnosis: preschool children with the 22q11.2 deletion. Genet Med. 2001;3:40-4.

24. Niklasson L, Rasmussen P, Oskarsdottir S, Gillberg C. Attention deficits in children with 22q.11 deletion syndrome. Dev Med Child Neurol. 2005;47:803-7.

25. Campbell LE, Daly E, Toal F, Stevens A, Azuma R, Catani M, et al. Brain and behaviour in children with 22q11.2 deletion syndrome: a volumetric and voxel-based morphometry MRI study. Brain. 2006; 129(Pt5):1218-28.

26. van Amelsvoort T, Daly E, Henry J, Robertson D, Ng V, Owen M, et al. Brain anatomy in adults with velocardiofacial syndrome with and without schizophrenia: preliminary results of a structural magnetic resonance imaging study. Arch Gen Psychiatry. 2004;61:1085-96.

27. Anaclerio S, Di Ciommo V, Michielon G, Digilio MC, Formigari R, Picchio FM, et al. Conotruncal heart defects: impact of genetic syndromes on immediate operative mortality. Ital Heart J. 2004;5: 624-8.

28. Iserin L, de Lonlay P, Viot G, Sidi D, Kachaner J, Munnich A, et al. Prevalence of the microdeletion 22q11 in newborn infants with congenital conotruncal cardiac anomalies. Eur J Pediatr. 1998;157:881-4.

29. Driscoll DA. Prenatal diagnosis of the 22q11.2 deletion syndrome. Genet Med. 2001;3:14-8. 